\title{
Food-Medicine Interface and its Application in International Level, Comparative Jurisdictions and Sri Lankan Legal Context
}

\section{Charith Amidha Hettiarachchi*}

Visiting Scholar, Department of Public Health, Faculty of Heath, University of Technology Sydney, Australia and Post-Doctoral Scholar, Ministry of Health, Sri Lanka

Email - dr.charith@gmail.com Mobile - +94714442425,

ORCHID number: https://orcid.org/0000-0002-7329-6581

\section{Sanath Sameera Wijesinghe}

$\mathrm{PhD}$ Researcher, Faculty of Law, school of Law, Queensland University of Technology, Brisbane, Australia and Lecturer in Law, Department of Legal Studies, The Open University of Sri Lanka

Email - sanathwijesinghe@gmail.com

\section{Abstract}

There has been a growing interest in the Food-medicine interface due to its legal and commercial importance with the development of both food and medicine industries. Food and medicine--even though some foods have therapeutic (curative or preventive) properties--are two different entities, regulated by different legal regimes. Hence, the distinction between food and medicine is crucial in order to protect the interests of consumers. This study is a doctrinal review on the food-medicine interface at international level with particular reference to its application in the Sri Lankan context.

There seems to be a lack of global policy consensus or coherent legal regime regarding the foodmedicine interface, and the same is true for Sri Lanka. Both Western and Ayurveda drugs are registered with the competent authorities in Sri Lanka: The National Medicines Regulatory Authority and Ayurveda Department, respectively. To register a food as a drug, these authorities can use two criteria: 1. recognised medicinal properties and 2. therapeutic (curative or preventive) purpose of consumption. The registration of a food commodity by these two competent authorities can be taken as a criterion to identify them as medicines thus, to differentiate them in a legal sense from food per se. From a legal perspective, any food not registered by one of these two authorities-irrespective of their therapeutic (curative or preventive) benefits - is considered to be simply a food. This demarcation of the food-medicine interface could be used by industries for the purpose of marketing strategies and law enforcing officers for the purposes of law enforcement.

\section{Key words}

Food-Medicine Interface, Food, Medicine, Dietary Supplements, Medicinal Food, Food Law 


\section{Introduction}

Food and medicine are essential for human survival. Both commodities are also invariably profitable for industry actors and often are associated with immense interference of the industries and their competitive marketing strategies. Food may have therapeutic (curative or preventive) effects in addition to its nutritious values. Where food is thought to have a potential therapeutic effect, this is used as a marketing strategy by industries to increase demand. In this backdrop, food and medicine related laws should be well developed and subject to routine review to prevent potential misleading of consumers. Since food and medicine are two different commodities, they are regulated by different legislations; hence, the distinction between food and medicine is crucial in order to apply and implement the respective laws.

Due to the rapid expansion of the scope of food-medicine interface, sub-entities have emerged under different terminology such as medicinal foods, borderline products, dietary supplements, food supplements, complimentary medicines, and nutraceutical products. However, presence of subentities itself is not useful unless a clear guideline is available to differentiate food from medicine.

The main objective of this review is to analyse the demarcation between food and medicine through the lens of selected comparative jurisdictions, and thereby, to assess the adequacy of Sri Lankan legal regime that apply on both commodities.

\section{Methodology}

The study was a doctoral (on principles) research which was based on two phases. First, an extensive review of literature was cone, and second, a comparative legal research on selected jurisdictions was conducted. In the literature review phase, international legal instruments, legislations of the selected jurisdictions and Sri Lanka laws have been used as primary sources. Literature was collected through official websites of respective legislature, judicature and administrative bodies. As secondary sources, scholarly articles, books, and research reports have been used. The in-depth review was conducted under entities of food, medicine, dietary supplement, medicinal food, judicial interventions and food-medicine interface. In second phase, India, Australia, the United States of America, European Union, and the United Kingdom have been selected as comparative jurisdictions considering the contemporary legal developments of these countries in respect of regulating food and medicine.

\section{Results and Discussion \\ Food}

Identification of food is based on the scope of the definitions stipulated in legislation and standards. This part examines the definition of food by looking at international standards, legislation of selected jurisdictions and Sri Lankan law. The legal definition of food is important as it provides a clarification to differentiate food from non-food items such as medicines. Both Codex Alimentarius and World Health Organization exclude medicines from the definition of food. Codex Alimentarius defines food as 'any substance, whether processed, semi-processed or raw, which is intended, for human consumption, and includes drinks, chewing gum and any substance which has been used in the manufacture, preparation or treatment of 'food' but does not include cosmetics tobacco or substances used only as drugs' (Codex Alimentarius Commission, 2005. Substances that are used as drugs or medicines are excluded in the food definition by World Health Organization too (World Health Organization, 2004). Even though medicines are also intended for human consumption, both definitions explicitly exclude medicines from the scope of food. However, an exact demarcation between these two commodities remains vague at international level. 
The comparative legislation provides a more precise definition for food while excluding medicines. The definition of food encapsulated in the United Kingdom Food Safety Act of 1990 defines food by specifically excluding medicines. The Food Act of 2003 of New South Wales, Australia explicitly excludes medicines from the definition of the food by stipulating - "food does not include a therapeutic good within the meaning of the Therapeutic Goods Act of 1989" (NSW Legislation, 2003). A similar approach is followed in developing countries like India, which defines food with specific inclusions and exclusions. Among other things, drugs and medicinal products appear in the exclusion list in Indian legislation. (Ministry of Law and Justice, 2006).

The Sri Lankan Food Act of 1980 defines food as an article manufactured, sold or represented for use as food or drink for human beings and includes any article which ordinarily enters in to or is used in the composition or preparation of food (Government Publication Bureau, 1980). The definition of food is confined to substances for human consumption, and hence, excludes animal feed; however, it does not explicitly exclude medicines. However, the Food and Drug Act of 1949 which is the predecessor of the current Food Act of 1980 had defined food as "food or drink for human consumption, other than drugs and ...." (Government Press, 1949). It seems that early Sri Lankan law was more precise than the current law in explicitly excluding drugs from the definition of food. Even though some inclusions are stated, it has failed to state important exclusions. Therefore, it is questionable whether items such as Ayurveda herbal products -- which are mostly 'food' or 'food derivatives' -- fall under the purview of food or not. The law-enforcing officers of Sri Lanka have stated that confusion arises due to the lack of differentiation between some Ayurveda herbal products and food. Further, there remain uncertainties as to which of these products are covered by food laws or Ayurveda laws in Sri Lanka (Hettiarachchi, 2017). Thus, the demarcation between food and medicine under Sri Lankan law remain much more unclear when compared to the other countries.

\section{Medicine}

The definition of medicine stipulated in Therapeutic Goods Act of 1989 of New South Wales, Australia (Federal Register of Legislation, 2020) and the Drug and Cosmetic Act of 1940 of India and the Medicines Act of 1968 of United Kingdom (Legislation.Gov.UK, 2020) provides a similar meaning to that of the definition embodied in National Medicines Regulatory Authority Act of 2015 of Sri Lanka, irrespective of the different terminology used in those legislations. According to the National Medicines Regulatory Authority Act of 2015 of Sri Lanka, medicine includes 'any substance or mixture of substances manufactured, sold, offered for sale or represented for use in the diagnosis, treatment, mitigation or prevention of disease, abnormal physical states or the symptoms thereof in man or animal; and restoring, correcting or modifying functions of organs in man or animal; a medicine or combination of medicine ready for use and placed on the market under a special name or in a characteristic form, both patent and non-proprietary preparations; a product made out of medicinal herbal extract; nutraceutical with therapeutic claims; and vaccines and sera, but does not include an Ayurvedic medicine or Homoeopathic medicine' (Government Publication Bureau, 2015). Therefore, medicine is simply identified as a substance that used for diagnosis, treatment, mitigation or prevention of a medical condition. The Sri Lankan definition of medicine excludes Ayurveda medicines from its scope. Hence, Ayurveda medicines do not come under the purview of National Medicines Regulatory Authority Act of 2015 and but fall in the scope of Ayurveda Act of 1961.

The United Kingdom law defines herbal remedy as a medicinal product consisting of a substance produced by subjecting a plant or plants to drying, crushing or any other process, or of a mixture whose sole ingredients are two or more substances so produced, or of a mixture whose sole ingredients are one or more substances so produced and water or some other inert substance, in addition to its definition of medicine (Legislation.Gov.UK, 2020). The Sri Lankan Ayurveda Act of 
1961 does not define Ayurveda medicines even though the law is providing provisions to register Ayurveda medicines (Government Publication Bureau, 1961). In Sri Lanka, Ayurveda medicines are recognized by an expert committee called 'Ayurveda Suthra Committee' in the absence of a legal definition. The lack of coherent definition for Ayurveda medicines can be considered as one of the loopholes of existing Sri Lankan law.

\section{Dietary supplements}

A dietary supplement is an entity which has a functional link with both food and medicine. Vitamins and minerals are the most common items covered in the scope of Dietary supplement. The parent category of this subcategory is determined by local legislations and standards. The United States legally defines dietary supplement as a product, other than tobacco, intended to supplement the diet that contains at least one or more of the following ingredients: a vitamin, a mineral, an herb or other botanical, an amino acid, or a dietary substance for use to supplement the diet by increasing the total dietary intake; or a concentrate, metabolite, constituent, or extract or combination of any of the previously mentioned ingredients. In addition, the United States Dietary Supplement Health and Education Act of 1994 - subcategorized this entity under the parent category of food and not under medicine. It must display the statement - 'dietary supplements'- on the label (Food and Drug Administration, 2019). The European Union recognises this entity as food supplements and recognizes as a food and not as a medicine while food supplements can be presented as capsules, tablets, pastilles, powder, drops or liquids (Devla et al., 2011). India does not specifically regulate this entity; however, it is regulated generally under Food Safety and Standard Act of 2006 (Devla et al., 2011) recognising dietary supplements as nothing other than foods. All these legal definitions are in line with the International Food Code -- Codex Alimentarius - which recognizes a food supplement as a distinct entity under the parent category of food (Codex Alimentarius, 2005). In contrast, Australia, by the Therapeutic Goods Act of 1989, has recognised dietary supplements as a medicinal subcategory called complementary medicines. The subcategory includes vitamin, mineral and nutritional supplements; therefore, dietary supplements are not foods but medicines in Australia (Therapeutic Goods Administration, 2020).

The Sri Lankan National Medicines Regulatory Authority Act of 2015 has recognized a medicinal subcategory called nutraceutical products (Government Publication Bureau, 2015). The word nutraceutical is combined from the words nutrition and pharmaceutical and is a food or fortified food product that not only supplements the diet but also assists in treating or preventing disease, that is, provides medical benefits (Drugs.com, 2020). According to the Sri Lankan National Medicines Authority Act of 2015, a nutraceutical product means a product isolated or purified from food which is generally sold in medicinal form not usually associated with food and which provides physiological benefit or protection against chronic diseases (Government Publication Bureau, 2015). Items which come under the definition of dietary supplements are compatible with this definition. On the other hand, dietary supplements such as vitamins and minerals already have been registered as medicines at the National Medicines Regulatory Authority of Sri Lanka (National Medicines Regulatory Authority, 2020). Therefore, it is clear that in Sri Lanka, the entity of dietary supplement is a type of medicine and not a type of food, making it similar to that of Australian law rather than international standards and the laws of other jurisdictions.

\section{Medicinal Foods}

The concept of medicinal food is identified as a specific entity by the law of United States. The United States Orphan Drug Act of 1983 defines medicinal food as "food which is formulated to be consumed or administered enterally under the supervision of a physician and which is intended for the specific dietary management of a disease or condition for which distinctive nutritional requirements, based on recognized scientific principles, are established by medical evaluation (Food 
and Drug Administration, 2018). This definition emphasises that medicinal food is a specific type of food which has medicinal characteristics and therefore is considered to be a subcategory of food. Medicinal food is exempted from nutrition labelling requirements (Lewis et al., 2019). Alschulter (2011) comments on this definition further, stating that a medicinal food should be labelled for a specific medical disease or condition that has distinctive nutritional requirements. Some experts believe that all foods prescribed by physicians or foods that may be of some benefit to people who are sick are not medical foods. Medicinal foods are distinguished from the category of foods for special dietary use by the requirement that medical foods are intended to meet distinctive nutritional requirements of a disease or condition, to be used under medical supervision, and are intended for the specific dietary management of a disease or condition (Centre for Food Safety and Applied Nutrition, 2016).

Neither the Sri Lankan National Medicines Regulatory Authority Act of 2015 nor the Food Act of 1980 have included the term medicinal food. However, the Sri Lankan National Medicines Regulatory Authority Act of 2015 recognized a medicinal subcategory called borderline product. A borderline product has combined characteristics of medicines and foods, medicines and medical devices, or medicines and cosmetics (Government Publication Bureau, 2015). This Act further stipulates criteria for a borderline product: 1. the intended use of the product (or its primary function) and its mode of action; 2. the therapeutic claims that the manufacturer makes about the product (claims to treat or prevent disease or to interfere with the normal operation of a physiological function of the human body); 3. the pharmacological active substance, if any, used in the product; 4. the concentrations of the active substances; 5 . the level of efficacy of the active substance of the product; and 6. the ingredients used and the concentrations at which they are used (Government Publication Bureau, 2015). These criteria have shifted the borderline product to be more therapeutic in nature rather than to be more nutritious. Therefore, under Sri Lankan law, a borderline product does not bear the same meaning as medicinal food in the United States.

Currently, the concept of medicinal food is not widely developed globally. It has been suggested that medicinal food be used as a sub-category of food distinct from a drug by updating policies and amending regulations which will support for the marketing development of the category. Globally, food industries have already taken the advantage of the absence of strong legal recognition. Given that the definition of medicinal food is narrow, different types of food have been excluded from the scope of medicinal food; however, manufacturers attempt to market such excluded types of food as medicinal foods (Lewis et al., 2019).

The term 'functional food' is also often used on labels; however, only for the industrial purposes as it has not been defined and mandated by law. The functional foods are usually fortified foods, which are already regulated as food. Manufacturers cannot make specific condition and disease claims on labels of functional foods as they can for medicinal foods (Alschuler, 2011).

Some food is self-declared by companies as food for medicinal purposes, even though such ex parte declarations do not fit within the standards or legal definitions. Such food items are often sold online without proper medical supervision or authority. Sometimes the same items (e.g., chewing gums containing vitamins) are sold as a food and at other times as a medicine. If such an item is considered to be a food, the sugar content must be declared; and if such an item is defined as a medicine, it only is required to display "contains sugar" on its label (Harvey, 2019). Such complexities warrant a clear distinction between food and medicine.

\section{Judicial Interventions}

The Food and Drug Administration of the Unites States had issued warning letters for foods which are marketed as medicinal foods and may not fit for the criteria of medicinal food, mentioning that the label/advertisement is illegal (Hoadley, 2011). The Supreme Court in Victoria, Australia 
decided that 'foods' and hydration given to a 68 year old patient with severe dementia are medical procedures rather than food and therefore can be legally refused (Zinn, 2003). In an Indian legal case, Cadila Pharmaceuticals Ltd. vs State of Kerala, it was decided that dietary supplements (vitamin capsules) fit into the definition of 'drugs' according to the Drugs and Cosmetics Act of 1940 (Indian Kanoon, 2019a). Similarly, in Narendra Sahi \& Anr. vs State of Jharkhand, the court decided that a food supplement was considered to be a drug according to the provisions stipulated under Drugs and Cosmetics Act of 1940 of India (Indian Kanoon, 2019b).

\section{Food-Medicine Interface}

As seen in the above analysis, the food-medicine interface has attracted a growing interest worldwide. Eckert (2015) opines that it is not clear whether botanical products with health benefits should be defined as a food or medicine. These products are being consumed by people for their health benefits, have become a part of the routine diet, and are widely available. Eckert further emphasises the importance of the availability of a precise legal framework to be applied. Lack of relevant legal authority on the food-medicine interface could have a considerable impact, particularly on the countries with vast cultural and racial diversities. For example, there is no single criterion in Bangladesh for women to differentiate food and medicine; hence, women consider various factors like age, education, availability, purpose, consistency, and taste are not relevant to intrinsic characteristics of food/drug (Jennings et al., 2015). This vagueness persists in India also, as the food-medicine interface depends on cultural perspectives. Since India has huge cultural diversity, the food-medicine interface is seen to be complex, as various types of plant-based foods are used as medicines in various cultures (Esakkimuthu et al., 2018).

A criterion being used in Australia to determine the food-medicine interface is based on few simple questions. Those are: 1. Is the product for oral use for humans? 2. Is there a declaration (as per Therapeutic Good Act) in relation to the product that it is a therapeutic good? 3. Is the product covered by a declaration (as per Therapeutic Good Act)? 4. Is the product 'goods for which there is a standard' in the Food Standards Code? 5. Is the product represented in any way to be for therapeutic use; or likely to be taken [by someone] to be for therapeutic use because of the way in which it is presented; or likely to be taken [by someone] to be for therapeutic use for any other reason? 6. Is the product in a class of goods the sole or principal use of which is, or ordinarily is, a therapeutic use? (Therapeutic Goods Administration, 2020). The answers to these questions are utilized in a step-wise manner to lead to a satisfactory differentiation between food and medicine. However, some of the questions are subjective, which has made the food-medicine interface still somewhat indistinct in Australia.

When considering the Sri Lankan situation, there is no distinct demarcation between food and medicine, and in addition, no standard guideline available to differentiate between the two entities clearly. The absence of distinct criteria affects the implementation of both food as well as medicinal laws which in turn leads to confusion among law-enforcement officers and manufacturers.

\section{Conclusions and recommendations}

There is no single accepted distinct boundary for the food-medicine interface world-wide, as different jurisdictions and standards seemed to be applied differently. Similar to other jurisdictions, the demarcation between food and medicine remains indistinct in the Sri Lankan legal context. Sri Lankan legal definitions of medicines and its subcategories like borderline products and nutraceutical products outline the scope of medicine in clear terms; however, the legal definition of food is not precise and appears to be too broad. This creates a difficulty in clarifying the foodmedicine interface which ultimately matters in smooth registration and legislative procedures for both food and medicines. 
Most of 'foods' have beneficial health effects (curative or preventive) for medical conditions. A food could be categorized under medicine when: 1. medicinal properties are recognised; and 2. the purpose of consumption is therapeutic (curative or preventive). These criteria should be evaluated by a competent authority such as the 'National Medicines Regulatory Authority' for Western medicines and 'Ayurveda Suthra Committee' for Ayurveda herbal drugs in Sri Lanka. Sri Lankan Ayurveda herbal products (herbal drugs) are registered at the Ayurveda Department while Western medicines are registered at the National Medicines Regulatory Authority, as required by the law. There would seem to be no legal barrier to considering both institutions as competent authorities to regulate, monitor and implement these suggested criteria. As both Western and Ayurveda drugs are registered in their respective authorities, this registration could be taken as a criterion to identify medicines and to differentiate from food for the marketing purpose of industries and for the prosecution purpose of law-enforcement officers.

Other 'foods', irrespective of their therapeutic (curative or preventive) properties, which are not registered in National Medicines Regulatory Authority or Ayurveda Department in Sri Lanka could be categorized under food. The definition of food stipulated in the Sri Lankan Food Act of 1980 needs to be amended to explicitly exclude medicines, dietary supplements, nutraceutical products and Ayurveda herbal products. In addition, the Ayurveda Act of 1961 of Sri Lanka needs to be amended to include a definition for Ayurveda Medicines. Such considerations and revisions would contribute to establish a pragmatic legal regime for the food-medicine interface in Sri Lanka. Table 1 summarizes some of the needed definitions.

Table 1. Simple theoretical and practical definitions of food and medicine

\begin{tabular}{|c|c|c|}
\hline & Theoretical definition & Practical definition \\
\hline Medicine & $\begin{array}{l}\text { A substance used for } \\
\text { diagnosis, treatment, } \\
\text { mitigation or prevention } \\
\text { of a medical condition. }\end{array}$ & $\begin{array}{l}\text { A substance which is registered } \\
\text { at a competent medicinal } \\
\text { (Western or Ayurveda) authority. } \\
\text { Competent authority may register } \\
\text { as a medicine a substance - } \\
\text { among other things - that is } \\
\text { intended to be eaten or drunk by } \\
\text { humans, if following two criteria } \\
\text { are satisfied: } \\
\text { 1. recognition of medicinal } \\
\text { properties and, } \\
\text { 2. therapeutic (curative or } \\
\text { preventive) purpose of } \\
\text { consumption. }\end{array}$ \\
\hline Food & $\begin{array}{l}\text { A non-medicinal substance } \\
\text { which is intended to be eaten } \\
\text { or drunk by humans. }\end{array}$ & $\begin{array}{l}\text { A substance } \\
\text { 1. intended to be eaten or drunk } \\
\text { by humans and, } \\
\text { 2. not registered at a competent } \\
\text { medicinal (Western or } \\
\text { Ayurveda) authority. }\end{array}$ \\
\hline
\end{tabular}

\section{Conflict of Interest}

No competing interests. 


\section{Funding}

No funding was necessary.

\section{Acknowledgements}

The authors pay gratitude to the Post Graduate Institute of Medicine, University of Colombo and Ministry of Health Sri Lanka for their support and guidance and to the academic and non-academic staff of Department of Public Health, Faculty of Health, University of Technology Sydney, Australia for their valuable assistance.

\section{References}

Alschuler L. (2011). The Truth About Medical Foods. Perhaps it's not as oxymoronic as it sounds. Natural Medicine Journal 2011;3(9). https://www.naturalmedicinejournal.com/journal/2011$\underline{09 / \text { truth-about-medical-foods }}$

Camire, M.E. and Kantor, M.A. (1999). Dietary supplements: nutritional and legal considerations. Food technology (Chicago) 53(7):87-96.

Codex Alimentarius. (2005). Guidelines for vitamin and mineral food supplements. Codex Alimentarius Commission.

Devla M.N., Acharya S.R., Acharya N.S., Kumar V. (2011). Dietary supplements: a legal status in India \& in foreign countries. International Journal of Pharmacy and Pharmaceutical Sciences 3(3). https://innovareacademics.in/journal/ijpps/

Drugs.Com. (2020). Nutraceutical products. https://www.drugs.com/drug-class/nutraceuticalproducts.html

Eckert G.P. (2015). The Ethnopharmacology of the Food-Medicine Interface: The Example of Marketing Traditional Products in Europe. In: Ethnopharmacology (eds. M. Heinrich \& A.K. Jager), John Wiley \& Sons, Ltd. https://www.researchgate.net/.doi.10.1002/9781118930717.ch21

Esakkimuthu S. et al. (2018). A Study on Food-Medicine Continuum Among the NonInstitutionally Trained Siddha Practitioners of Tiruvallur District, Tamil Nadu, India. Journal of Ethnobiol Ethnomed 14(1):45. doi: 10.1186/s13002-018-0240-9.

Federal Register of Legislation. (2020). Therapeutic Goods Act 1989. NSW. https://www.legislation.gov.au/Details/C2020C00235

Food and Drug Administration. (2018). Ophan Drug Act.

https://www.fda.gov/industry/designating-orphan-product-drugs-and-biological-products/

Food and Drug Administration. (2019). Dietary supplement. https://www.fda.gov/food/dietarysupplements

Government Press. (1949). Food and Drug Act of 1949. Sri Lanka Government Press.

Government Publication Bureau. (2015). National Medicines Regulatory Authority Act of 2015. Sri Lanka Government Publication Bureau.

Government Publication Bureau. (1961). Ayurveda Act of 1961. Sri Lanka Government Publication Bureau.

Harvey K. (2019). Food-medicine interface problems. FSANZ Harvey Presentation. https://www.medreach.com.au/food-medicine-interface-problems/ 
Hettiarachchi C.A. (2017). Compliance of labels of beverages to the food labelling regulation and effectiveness of an advocacy package in improving adherence to labelling regulations by food industry. MD theses, Post Graduate Institute of Medicine, University of Colombo.

Hoadley J.E. (2011). U.S. regulation of functional foods. In: Functional Foods. pp. 41-63. Woodhead, $2^{\text {nd }}$ edition. Doi: 10.1533/9780857092557.1.41

Indian Kanoon. (2019a). Cadila Pharmaceuticals Ltd. vs State of Kerala And Ors. https://indiankanoon.org/doc/3493/

Indian Kanoon. (2019b). Narendra Sahi \& Anr. vs State of Jharkhand. https://indiankanoon.org/doc/178278186/

Jennings H.M. et al. (2015). Food or Medicine? The Food-Medicine Interface in Households in Sylhet. Journal of Ethnopharmacol 5:167:97-104. DOI: 10.1016/j.jep.2014.09.011

Legislation.Gov.UK website. (2020). Medicines Act of 1968 United Kingdom. https://www.legislation.gov.uk/ukpga/1968/67

Lewis C.A., Jackson M.C., Bailey J.R. (2019). Understanding medical foods under FDA regulations. In: Nutraceutical and Functional Food Regulations in the United States and around the World (eds. D. Bagchi), Charlotte Cockle, $3^{\text {rd }}$ edition. doi: 10.1016/B978-0-12-816467-9.00015$\underline{0 . \operatorname{ch} 15}$

Ministry of Law and Justice. (2006). Food Safety and Standard Act of 2006. Ministry of Law and Justice, India.

National Medicines Regulatory Authority. (2020). Registered Products. Government of Sri Lanka. Available at nmra.gov.lk/

NSW Legislation. (2020). Food Act of 2003. Australia. https://www.legislation.nsw.gov.au

Therapeutic Goods Administration. (2020). An overview of the regulation of complementary medicines in Australia. https://www.tga.gov.au/overview-regulation-complementary-medicinesaustralia

Therapeutic Good Administration. (2020). Food-Medicine Interface Guidance Tool. Department of Health. Australia. https://www.tga.gov.au/food-medicine-interface-guidance-tool-fmigt

Zinn C. (2003). Court rules food and hydration are treatment. British Medical Journal 7:326(7401):1233. doi: 10.1136/bmj.326.7401.1233-a 